Espacio, Tiempo y Forma, Serie II, Historia Antigua, t. 17, 2004-2005, págs. 237-250

\title{
El final de las guerras astur-cántabras y la desmilitarización del ejército romano en territorio de los astures
}

\author{
The end of the "astur-cántabras" wars and the desmilitarization \\ of the Roman army in the territory of the "astures"
}

\author{
NARCISO SANTOS YanguaS \\ Universidad de Oviedo
}

\section{RESUMEN}

La historia militar del territorio de los astures se recoge con bastante precisión en la documentación antigua, especialmente en las inscripciones latinas y los restos materiales procedentes de las últimas excavaciones arqueológicas. Estos datos nos permiten trazar una serie

de períodos a través de los cuales se desarrolla la política militar, que, arrancando de Augusto, desembocará en un ejército para la paz en el siglo II d.C.

Analizamos aquí el primero de ellos, constituido por la etapa de reajuste de dicho ejército (años 19-15 a.C. a 20 d.C.).

PALABRAS CLAVE:

Astures, Hispania, Petavonium, Pax Romana, legio VI Victrix, legio X Gemina), legio IIII Macedonica

\section{ABSTRACT}

The military history of the astures's territory is pretty well documented in old sources, above all in Latin inscriptions and material evidence found in the most recent archaeological excavations. This set of data allows the establishment of a number of periods during which the military policy was developed, from the Augustan age to the formation of an army for peace during the second century A.D. We analyse here the first of them, which corresponds to the age of readjustment of the said army (1915 B.C. till 20 A.D.).

\section{KEYWORDS:}

Astures, Hispania, Petavonium, Pax Romana, legio VI Victrix, legio X Gemina, legio III Macedonica

\section{INTRODUCCIÓN}

Inmediatamente después de la finalización de las guerras astur-cántabras (año 19 a.C. como referente), y a pesar de que las fuentes escritas antiguas documentan en las décadas posteriores algunas revueltas por parte de las poblacio- 
nes septentrionales hispanas ${ }^{1}$, se iba a producir una fase de reajuste en cuanto a las unidades militares integrantes del ejército romano que habían participado en los enfrentamientos bélicos.

Este proceso, que implicaría una desmilitarización paulatina del Norte peninsular, no significaría sin embargo que Augusto alterase los elementos fundamentales de su estrategia militar con respecto al territorio de los astures sino que, a medida que la pax romana iba apaciguando los últimos reductos de resistencia indígena, la necesidad de efectivos militares establecidos como elemento represivo se fue haciendo cada vez menos acusada².

Debido a ello ciertos cuerpos de tropas legionarias, que habían tomado parte en los combates de los años precedentes, irían abandonando poco a poco el suelo hispano, uniéndose igualmente a esta dislocación algunas de las unidades auxiliares que dependían de los mismos ${ }^{3}$.

No obstante, la historia militar del cuadrante noroccidental hispano, que abarca las décadas inmediatas hasta completar el primer siglo de presencia romana en nuestro territorio (hasta el año 70 d.C. aproximadamente), puede considerarse en su conjunto como una mera prolongación de los parámetros de funcionamiento militar que habían tenido lugar en el transcurso de las guerras ${ }^{4}$.

\section{FUENTES DE INFORMACIÓN}

Por desgracia la documentación de que disponemos a este respecto no es lo suficientemente amplia como para llegar a conclusiones definitivas, ya que las noticias que nos pueden aportar las fuentes escritas (literarias y epigráficas), a pesar de los últimos descubrimientos, resultan todavía escasas (por no calificarlas de insuficientes).

En este sentido constituye una base material cada vez más aprovechable para nuestros propósitos el análisis de las inscripciones militares en general relacionadas con los asentamientos castrenses, a pesar de que en unos casos sea mucho más abundante que en otros y se correspondan ya en el tiempo con la historia militar de dichas unidades en las fases históricas posteriores ${ }^{5}$.

\footnotetext{
1 Ver, por ejemplo, Dión Casio (Historia romana 54.4.2) con respecto al año 16 a.C., o CIL XI.395, correspondiente ya a la época de Nerón.

2 No vamos a analizar aquí, sin embargo, la importancia de los enclaves campamentales, tanto de las tropas legionarias como de los cuerpos auxiliares, muchos de los cuales darían origen a significativos centros de población.

3 Más detalles en N.SANTOS, «El ejército romano de conquista en el Norte peninsular» (en prensa).

4 Esta unidad de mando y estrategia fue planteada ya por A.GARCÍA Y BELLIDO en «El exercitus hispanicus desde Augusto a Vespasiano", AEA 34 (1961) 114 y ss.

5 Ver, por ejemplo, L.HERNANDEZ, Epigrafía romana de unidades militares relacionadas con Petavonium (Rosinos de Vidriales, Zamora), Valladolid 1999.
} 
De cualquier forma donde el avance en este campo ha sido más significativo es sin duda con respecto a la arqueología militar, puesto que en la última década y media las intervenciones en emplazamientos militares romanos y el contexto que les rodeaba han sacado a la luz nuevos datos en el Norte peninsular, incluida la identificación de alguna unidad de tropas auxiliares de la que no se tenía constancia hasta la fecha ${ }^{6}$.

Este llamativo progreso ha contado, entre otros alicientes, con el representado por la fotografía aérea, que ha permitido concretar el entorno del trazado de algunos de estos centros militares romanos pertenecientes a las diferentes guarniciones que integraban el ejército de ocupación en el territorio de los astures ${ }^{7}$.

Han sido, sin embargo, las excavaciones sistemáticas de los últimos años las que nos han permitido hacernos una idea aproximada acerca de las diferentes fases de la presencia de estos destacamentos militares (legiones y tropas auxiliares) que formaban parte del ejército de ocupación, así como de las características que encerraban sus recintos campamentales, algunos de los cuales se hallarían en el origen de ciertos centros urbanos de los astures y de las poblaciones próximas ${ }^{8}$.

En este sentido el territorio de los astures augustanos ha aportado todo un conjunto de novedades militares relacionadas con los emplazamientos castrenses de las legiones romanas estacionadas en dicho suelo en los años inmediatamente posteriores a las guerras astur-cántabras, en especial Astorga, León y, en menor medida, dado que su emplazamiento y contorno se hallaban ya perfectamente definidos, Petavonium (sin olvidar, en el ámbito de los cántabros, los campamentos, primero legionario y después de tropas auxuiliares, de Herrera de Pisuerga) ${ }^{9}$.

Con este bagaje de referencias es posible distinguir una serie de períodos en la historia militar romana del Norte peninsular (que es tanto como decir de toda Hispania), en primer lugar durante el primer siglo de presencia romana en territorio septentrional (desde el final de las guerras astur-cántabras y durante la dinastía julioclaudia), y a continuación en tiempos de las dinastías de los Flavios y Antoninos.

Así pues, tras finalizar los enfrentamientos militares con las poblaciones septentrionales hispanas se iba a abrir una etapa continuista desde el punto de vista de la estrategia militar romana, que únicamente se cerraría con la crisis de la guerra civil que representan los años 68-70.

6 Es el caso del ala Parthorum, que ocuparía el espacio campamental dejado por la legio IIII Macedonica en Herrera de Pisuerga. Cf. C. PÉREZ, «Pisoraca (Herrera de Pisuerga): Urbanismo militar y civil de época romana», Los orígenes de la ciudad en el Noroeste hipánico, Lugo 1999, p.550.

7 Ver, entre otros, J .del OLMO, «Arqueología aérea en tres núcleos campamentales romanos de Zamora y León», Brigecio 4-5 (1994-1995) 115 y ss.

8 Uno de los ejemplos más llamativos sería el de León. Cf. V. GARCíA MARCOS, «Novedades acerca de los campamentos romanos de León», Arqueología militar romana en Hispania, Madrid 2003, pp.167 y ss.

9 Más detalles en A. MORILLO, «Los campamentos romanos de la Meseta norte y el Noroeste: (un limes sin fronteras? », Los finisterres atlánticos en la Antigüedad, Madrid 1996, pp.77 y ss. 
Con tales antecedentes es posible distinguir, en el marco de la historia militar del Alto Imperio en el Norte peninsular, los siguientes períodos:

I) Una primera fase inmediata a los años de anexión del territorio nordoccidental hispano (19-15 a.C. a 20 d.C.), que podemos calificar como «período de reajuste", de manera que el ejército romano de conquista se va reduciendo paulatinamente al compás que las necesidades militares, cada vez menos acusadas, darían paso a una desmilitarización de las legiones participantes en las guerras, así como a un asentamiento definitivo de las que quedan en los que serán sus campamentos estables definitivos ${ }^{10}$;

II) A continuación tendría lugar la etapa de consolidación de las formas de vida romanas en el Norte peninsular (años 20 a 68), proceso al que sin duda contribuiría en gran medida este ejército de ocupación romano, no tanto por su actividad militar de carácter represivo cuanto por su concurso en las actividades de tipo civil, favoreciendo así la implantación de los parámetros propios de la pax romana;

III) Seguidamente, y un poco a manera de visagra entre el ejército del período de los Julio-Claudios y el que sería propio de los Flavios y Antoninos, contamos con un intervalo de menos de 2 años (del 68 al 70), en el que las características del ejército de Augusto se verían alteradas sustancialmente por los avatares políticomilitares que entrañaría el conocido como «año de los 4 emperadores»;

IV) De inmediato asistiremos a la fase de la dinastía de los Flavios, incluido Nerva (años 70 a 98), momento en que el ejército romano establecido en suelo hispano experimentará algunos cambios con respecto no sólo a su número sino también en relación con el sistema de enrolamiento de sus componentes, a lo que sin duda contribuiría en gran medida la política general de Vespasiano, encaminada tanto al desarrollo del sistema urbano como al aprovechamiento de los recursos económicos del Norte peninsular ${ }^{11}$;

V) Por último, todo el siglo II de nuestra era (años 98 a 193), ocupado por los emperadores Antoninos, aunque en realidad solamente pertenecerían a tal dinastía desde Antonino Pío (año 138), por lo tanto dicho personaje y Marco AurelioLucio Vero y Cómodo: en estas décadas nos encontramos con un ejército permanente en una España pacificada, en la que la actividad desplegada por sus componentes (vexillationes de la legión VII Gemina y/o de las tropas auxiliares dependientes de ella) se vincula más con aspectos civiles (actividades mineras, construcción, reparación de calzadas...) que estrictamente militares ${ }^{12}$.

10 En cualquier caso no se puede hablar de un «ejército de frontera», puesto que no existe un limes definido en el cuadrante nordoccidental hispano similar a otros trazados por el primer emperador romano, sino simplemente de unas fuerzas militares que formarían parte del «ejército de ocupación».

11 Más detalles en A.B.BOSWORTH, «Vespasian and the Provinces. Some Problems of the Early 70's A.D.», Athenaeum 51 (1973) 49 y ss.

12 Ver, entre otros, J.M.ROLDÁN, «El ejército hispánico de Vespasiano a Diocleciano: una institución de la España romana imperial», Estudios en homenaje a D.Claudio Sánchez Albornoz en sus noventa años, Buenos Aires 1983, pp. 563 y ss. 


\section{EL PERÍODO DE REAJUSTE MILITAR}

El final de los combates de los romanos con las poblaciones astures, que cierra Agripa, daría paso a una fase temporal en la que la paz iría anidando poco a poco en el marco de las comunidades indígenas del Norte peninsular.

Se produciría así la salida casi inmediata de dicho suelo de buena parte de las unidades militares que habían tomado parte en los enfrentamientos bélicos mantenidos durante la década del 29 al 19 a.C., al tiempo que la administración romana diseñaría los objetivos de una nueva política y estrategia militares, no destinadas ya a la guerra sino a la paz, es decir paulatinamente se iba dando paso a un ejército de ocupación que, aunque tiene su origen con Augusto, no se consolidará definitivamente más que con sus sucesores ${ }^{13}$.

La realidad militar del territorio hispano en los años inmediatos a la finalización de las guerras astur-cántabras nos viene recogida perfectamente por Estrabón al referirse a los distritos que se forman en esos momentos y que, salvo en un caso, contarían con destacamentos militares (legiones) en su territorio:

«Ahora que las provincias han sido asignadas unas al pueblo y al Senado, otras al emperador, la Bética fue entregada al pueblo (romano) y se le envia un pretor con un cuestor y un legado; su límite oriental se ha fijado en las cercanías de Castulo.

El resto pertenece al emperador; éste envia dos legados, uno pretorio y el otro consular: el pretorio con un legado gobierna la Lusitania, que limita con Bética y se extiende hasta el Duero y su desembocadura; esta región conserva en la actualidad el mismo nombre y en ella se encuentra la ciudad de Emerita.

La parte restante de Hispania, y la mayor, esta regida por el legado consular, que dispone de un ejército considerable, compuesto por 3 legiones, y tiene a sus órdenes 3 legados, de los cuales uno, con dos legiones, guarnece toda la región del Norte de Duero, llamada antes Lusitania y ahora Callaecia.

Añadíase a ésta la parte septentrional con los astures y los cántabros; por el país de los astures discurre el río Melsos, y a escasa distancia de él se encuentra la ciudad de Noega; un estuario cercano separa a los astures de los cántabros.

La región que se extiende desde allí hasta los Pirineos la gobierna el segundo legado con otra legión.

El tercer legado administra la parte interior, que abarca los pueblos llamados ya togados, como si dijéramos pacificados y que han adoptado, junto con la toga, la civilización y las formas de vida itálicas; son éstos los celtíberos y los que habitan a ambos lados del Ebro hasta el mar $>^{14}$.

Frente a lo que piensan otros investigadores creemos que los 3 legados de rango pretoriano, que dependían del gobernador de la Citerior Tarraconense, no

${ }^{13}$ A.MORILLO, «Fortificaciones campamentales de época romana en España», AEA 64 (1991) 159.

14 Geografía 3.4.20. 
comandaban una legión cada uno, sino que el que tenía asignada Callaecia-Asturia contaba con 2 cuerpos de tropas (legio VI Victrix y legio X Gemina), el legado de la segunda (Cantabria) contaba con uno solo (legio IIII Macedonica) y el distrito restante estaría desprovisto de tropas.

La primera circunscripción limitaba con el Duero al sur, el Atlántico al oeste y el Cantábrico al norte, mientras que por el este coincidiría con el propio de cántabros y astures (Sella y Esla) ${ }^{15}$, abarcando el territorio correspondiente a los 3 conventus jurídicos del Noroeste peninsular.

En dicho suelo se hallaban acantonadas 2 legiones, la VI Victrix y la $X$ Gemina, mientras que la IIII Macedonica correspondería al segundo de dichos distritos.

La presencia de 2 contingentes legionarios en la primera zona contaría con una base militar, explicable por la proximidad en el tiempo de las guerras y la participación de cántabros, astures y galaicos en la misma, pero también económica, debido a su enorme riqueza minera.

Será precisamente esa motivación económica la que hará que se mantengan estacionadas allí durante varias décadas estas unidades, puesto que hasta el año 63 d.C. no saldría del mismo la legio $X$ Gemina, permaneciendo como única tropa de guarnición la VI Victrix hasta ser reemplazada por la VII Gemina, acuartelada durante el Alto y Bajo Imperio en el campamento que daría origen a la ciudad de León ${ }^{16}$.

Causas militares y económicas harían necesario también el acuartelamiento de un cuerpo legionario en el segundo distrito, mientras que el tercero, región mucho más urbanizada y por ende romanizada, no necesitaba presencia de tropas, dado que además en dicho suelo no se explotarían recursos que precisasen una vigilancia y control a través de destacamentos militares.

El carácter militar de estos distritos (sobre todo los dos primeros) deriva de su configuración inmediata al final de las guerras de conquista del Noroeste peninsular y de su desaparición a medida que la paz iba arraigando y los cuerpos legionarios abandonaban el territorio hispano.

Dicha fase de presencia romana en el Norte peninsular vendría caracterizaría por una ocupación militar más acusada que las siguientes, puesto que iba a contar con estos 3 cuerpos legionarios además de las unidades de tropas auxiliares que dependieran de ellos.

15 Pomponio Mela, Chorographia 3.13; Plinio el Viejo, Historia Natural 4.111; Ptolomeo, Tablas geográfico-históricas 2.6.5-6... Cf. J.M.GONZÁLEZ, «Función divisoria del río Sella en la Antigüedad», Valdediós (1970) 39 y ss.

${ }^{16}$ F.VITTINGHOFF, «Die Entstehung von städtischen Gemeinwessen in der Nachbarschaft römischer Legionslager. Ein Vergleich Leóns mit den Entwicklungslinien im Imperium Romanum», Legio VII Gemina, León 1970, pp.339 y ss. 


\section{a. La legión IIII Macedónica}

Tradicionalmente se ha venido creyendo que llegaría a territorio hispano para formar parte del frente oriental desde los primeros momentos de las guerras asturcántabras, por lo que se hallaría sucesivamente bajo el mando de Cayo Antistio, Elio Lamia, Cayo Furnio y Silio Nerva antes de pasar a las órdenes de Agripa en el 19 a.C. ${ }^{17}$.

Sin embargo, este traslado al Norte peninsular ibérico tal vez no se produciría hasta ese último año, momento en que el yerno del primer emperador romano toma el mando de las operaciones militares, en cuyo caso es posible que reemplazara a la presumiblemente disuelta legio I (Augusta?) ${ }^{18}$.

En caso de haber alcanzado nuestro suelo en esos momentos lo haría al parecer en compañía de la cohors I Gallica como unidad de tropas auxiliares a sus órdenes $^{19}$.

Además, entre el conjunto de cuerpos militares dependientes de la legión IIII Macedónica en estos momentos se hallaría igualmente la cohors IIII Thracum equitata ${ }^{20}$.

Una vez finalizados los enfrentamientos bélicos en el Norte peninsular este cuerpo legionario acamparía en territorio ibérico formando parte de las tropas de ocupación: quedaría estacionado en la zona del frente cántabro, donde, una vez pacificada la región, tendría su campamento (entre los años 19 y 13) en Segisama Iulia ${ }^{21}$.

En cuanto a la denominación de dicho campamento la documentación antigua testifica que Augusto lo había asentado en los aledaños de un poblado indígena que recibía el nombre de Segisamo, de manera que, en el momento en que las unidades legionarias lo abandonaron, la población indígena sería obligada a bajar de sus emplazamientos montañosos y residir en dicho enclave, que pasaría a conocerse con el nombre de Segisama lulia ${ }^{22}$.

La legión IIII Macedónica abandonaría dicho acuartelamiento en el año 13 a.C., siendo Pisoraca, en el ángulo noreste del territorio de los vacceos, donde

17 Ver, por ejemplo, M.JUNKELMANN, Die Legionen des Augustus, Maguncia 1986, p.97.

18 J. M.ROLDÁN, "La incidencia del ejército romano en el poblamiento del N.O. de Hispania», Ejército y sociedad, León 1986, p.30. Otros autores, como J. GONZÁLEZ ECHEGARAY («Las guerras cántabras en las fuentes", Las guerras cántabras, Santander 1999, p.162), consideran que este destacamento legionario no llegaría a nuestro suelo al menos hasta después de la marcha de Augusto del mismo.

19 J.M.SOLANA, «El procreso de anexión del territorio de Palencia y su integración en la provincia Hispania Citerior», III Congreso de Historia de Palencia, Palencia 1990, pp.614 y 619.

20 S.CARRETERO, «El cuadrante noroeste peninsular en época romana: los efectivos militares y sus establecimientos», Brigecio 3 (1993) 56.

21 J.HERRÁN CEBALLOS, Cántabros, un pueblo indómito, Bilbao 2000, p.116.

22 Floro, Compendio de historia romana 2.33.57-60. Cf. J.RODRÍGUEZ, Historia de las legiones romanas, Madrid 2001, p.169 nota 723 y J.A.ABÁSOLO, «La ciudad de Segisamo», Los orígenes de la ciudad en el Noroeste hispánico, Lugo 1999, pp.585 y ss. 
acamparía, al tiempo que alguno de sus destacamentos pudo desplazarse mucho más al norte, tal vez con el fín de controlar directamente el territorio, como pudo ser, entre otros, el caso del documentado en Gigia (Gijón) ${ }^{23}$.

Posiblemente en el recinto campamental antes mencionado estaría establecido ya, antes de la llegada del grueso de este cuerpo legionario, uno de sus destacamentos, al parecer integrado por soldados de caballería ${ }^{24}$.

De esta manera algunos de sus componentes tomarían parte en los enfrentamientos derivados de la revuelta promovida por astures y cántabros en el año 16 a.C., que constituyó sin duda uno de los últimos coletazos de las guerras astur-cántabras $^{25}$.

Precisamente al finalizar tales combates un conjunto de veteranos de dicha legión, junto con los de otros cuerpos militares de la misma naturaleza, contribuirían a la fundación de Caesaraugusta en el 15-1426.

Desde su asentamiento de Pisoraca mantendría perfectamente la vigilancia del territorio cántabro, dedicando sus esfuerzos igualmente a controlar y permanecer operativa la red viaria de la zona, en especial los accesos a la Meseta norte por el valle del Pisuerga.

En ese contexto se explica la construcción de una vía, en un principio de carácter militar, que uniría Pisoraca con Flaviobriga (Castro Urdiales), en el litoral cantábrico, con el objetivo de que sirviese de cauce para un rápido desplazamiento de efectivos militares si era preciso ${ }^{27}$.

Ya en los primeros años de nuestra era (en concreto el 4) soldados de esta unidad legionaria contribuirían a la construcción de un puente sobre el río Rubicatus, en la localidad de Ad Fines (un enclave bastante alejado de su asentamiento campamental), pudiendo haber participado igualmente en otras obras de construcción en Barcino, igualmente en la costa mediterránea perteneciente a la provincia Citerior Tarraconense ${ }^{28}$.

23 N.SANTOS, Roma en Asturias, Oviedo 1991, p.195.

24 C.PÉREZ y otros, «Pisoraca, un interesante conjunto de yacimientos arqueológicos», Revista de Arqueología 120 (1991) 24.

25 Dión Casio, Historia romana 54.20.3.

26 Desde Caesaraugusta a Pompaelo legionarios de la legión IIII contribuyeron en algún momento a la construcción de la vía romana que unía ambos enclaves en la década del 15 al 5 a.C.n.e. Cf. M.BELTRÁN y G.FATÁS, Historia de Zaragoza (2): Caesaraugusta, ciudad romana, Zaragoza 1999, p.14.

27 A.E. 1981, n. ${ }^{\circ}$ 547. Cf. E.ILLARREGUI, «Camesa-Rebolledo, asentamiento militar al sur de Cantabria», Los orígenes de la ciudad en el Noroeste hispánico, Lugo 1999, pp.559 y ss.

${ }_{28}$ A.E. 1984, n. ${ }^{\circ}$ 607. Cf. G.FABRE y otros, «Á propos du pont de Martorell: la participation de I'armée à l'aménagement du réseau routier de la Tarraconaise orientale sous Auguste», Épigraphie Hispanique. Problèmes de méthode et de édition, París 1984, p.283, y M.MAYER e I.RODÁ, «La presencia de militares en la zona norte del conventus Tarraconensis (Hispania Citerior)», La hiérarchie (Rangordnung) de l'armée romaine sous le Haut-Empire, París 1995, p.322. 
Entre las tareas de este cuerpo legionario se hallarían las de contribuir a la recaudación de los impuestos (tributos), así como la de dirigir las levas de los reclutas destinados a formar parte de las tropas auxiliares que dependían de él.

Con el fín de poder cumplir todos estos objetivos se ha llegado a pensar que un destacamento de la misma estaría acuartelado en el antiguo campamento de la legión II Augusta, que se hallaría en los alrededores de luliobriga ${ }^{29}$.

En este mismo contexto algunos de los militares de la legión IIII Macedónica serían destacados hacia el suroeste de la Península, en concreto hacia la región minera de Sierra Morena (en los alrededores de Nertobriga), sin duda para contribuir al aprovechamiento de los recursos económicos de la zona ${ }^{30}$.

Sería en los años del cambio de era cuando este cuerpo legionario configuraría definitivamente su recinto campamental mediante la construcción de edificios consistentes, elaborados a base de piedra y adobe, que sustituirían a las tiendas de campaña anteriores.

\section{b. La legión VI Victrix}

Desconocemos la fecha exacta de su llegada a territorio hispano, a pesar de que este hecho iba a dar origen al segundo de los títulos que la acompañaron a lo largo de su historia (legio VI Macedonica Hispana Victrix Pia Fidelis Britannica Felix).

Aunque es posible que se encontrase ya en el Norte peninsular en el momento en que Augusto dirige las operaciones para someter a cántabros y astures, en cuyo caso sería asignada al frente occidental, al mando de Publio Carisio, gobernador de la provincia de Lusitania, tal vez su participación en los combates no se produjese con anterioridad al año 25 , puesto que sus veteranos no formarían parte de las deducciones que dicho legado imperial llevaría a cabo con vistas a la fundación de Emerita Augusta ${ }^{31}$.

Junto con la legión X Gemina, una vez sometidos los galaicos, tal vez permanecería acuartelada en dicho territorio, debido a lo cual las poblaciones de la zona no se atreverían a unirse a astures y cántabros en la fase final de las gue$\operatorname{rras}^{32}$.

29 A.RODRIGUEZ COLMENERO, Augusto e Hispania. Conquista y organización del Norte peninsular, Deusto 1979, p.181.

${ }_{30}$ M. ${ }^{a}$ P.GARCÍA-BELLIDO, «Labores mineras militares en Hispania: explotación y control», Arqueología militar romana en Hispania, Madrid 2003, pp.19 y ss.

${ }_{31}$ N.SANTOS, El ejército romano y la romanización de los astures, Oviedo 1981, p.41.

${ }^{32}$ C.TORRES, La Galicia romana, La Coruña 1982, p.100. 
Quizás esta participación destacada en los combates correspondientes a la guerra del Norte peninsular le serviría para recibir el apelativo que sería definitivo en su titulatura $(\text { Victrix })^{33}$.

Mientras tomaba parte en dichos enfrentamientos militares contaría con una serie de unidades de tropas auxiliares dependientes, entre las que se hallaría al parecer el ala Tautorum civium Romanorum ${ }^{34}$, que en realidad hemos de identificar con el ala Tauriana torquata Victrix civium romanorum ${ }^{35}$

Una vez finalizados los combates la legión VI Victrix pasaría a formar parte del ejército de ocupación, permaneciendo acampada en el frente astur (de los astures cismontanos), tal vez en los alrededores de Asturica Augusta, integrada en aquellos años en la provincia Transduriana (Hispania Superior), según todos los indicios de muy escasa duración tempora ${ }^{36}$.

Alrededor del año 5 a.C., una vez integrado dicho suelo en el marco de la provincia Citerior Tarraconense, este cuerpo militar (o alguno de sus destacamentos) parece haber contado con un campamento temporal, si no compartido, muy próximo al de la legión X Gemina, puesto que tenemos constancia de que ambos cuerpos legionarios contaban con oficiales comunes, incluyendo el legado (comandante) $)^{37}$.

En una fecha sin concretar (posiblemente entre los años 15 a 10 a.C.) la legión VI Victrix, sin salir del territorio de los astures cismontanos, encontraría acomodo en el mismo emplazamiento donde, algunas décadas después, se asentaría la legión VII Gemina, cuyo campamento con el paso del tiempo daría origen a la ciudad de León (Legio) ${ }^{38}$.

A este respecto es posible que dicha legión se hallase igualmente en la base de la fundación de Lucus Augusti en una fecha muy temprana (años 26-25 a.C.), por lo que el sentido de la misma sería claramente militar ${ }^{39}$; sin embargo, pocos años después (entre el 16 y el 13) dicho asentamiento sería desmilitarizado.

Soldados veteranos de la legión VI Victrix tomarían parte en el año 15-14 en la fundación colonial de Caesaraugusta, contribuyendo con su presencia al control de

${ }^{33}$ E.VAN DEN EYNDE CERUTI, «Las guerras cántabras», Historia de Cantabria I, Santander 1985, p.221.

34 A.GARCÍA Y BELLIDO, «El exercitus hispanicus desde Augusto a Vespasiano», p.136. sa).

35 J. I. SAN VICENTE, «La estela calagurritana de lulius Longinus Doles y el ala Tauriana», (en pren-

36 J.MANGAS («El premio de Augusto», La Aventura de la Historia 24 (2000) 97) considera que esta circunscripción territorial únicamente tendría vigencia entre los años 21 y 13 a.C.e. Cf. F.COSTABILE y O.LICANDRO, Tessera Paemiobrigensis. Un nuovo editto di Augusto dalla Transduriana provincia e I'imperium proconsulare del Princeps, Roma 2000.

37 Estrabón, Geografía 3.4.20. Cf. P.LE ROUX, Le Haut-Empire romain en Occident d'Auguste aux Sévères, París 1998, p.379.

38 E.MARTINO, León y las legiones, León 1992, pp.55-57 y 95-96.

39 Más detalles en A.RODRIGUEZ COLMENERO y C.CARREÑO, «Sobre Paulo Fabio Máximo y la fundación de Lucus Augusti», Estudios ofrecidos a A.Balil, Santiago de Compostela 1992, pp.389 y ss. 
la zona, al tiempo que algunos militares en activo de la misma cooperarían a la construcción de la vía de comunicación que enlazaba el nuevo centro urbano con Pompaelo.

Entre las funciones encomendadas a los componentes de este cuerpo legionario cabe destacar el control del territorio próximo a su campamento, así como la de contribuir a la administración de las provincias hispanorromanas del Norte peninsular, puesto que sabemos que algunos de estos legionarios servirían en las oficinas de los gobernadores de Lusitania y Tarraconense ${ }^{40}$.

\section{c. La legión X Gemina}

Alrededor del año 26 a.C. este cuerpo militar sería trasladado al Norte peninsular ibérico, encomendándosele el frente occidental a las órdenes de Publio Carisio, gobernador (legado imperial) de la provincia de Lusitania ${ }^{41}$, de manera que, en torno al año siguiente, contaría ya con un campamento en Asturica Augusta, en suelo correspondiente a los astures cismontanos (augustanos) ${ }^{42}$.

Su participación en los avatares de las guerras astur-cántabras parece haber tenido su final en torno al año 22 , momento en que las comunidades astures quedarían ya prácticamente en estado de sumisión ${ }^{43}$.

Una vez finalizados los combates en el 19, la legión X Gemina permanecería acampada en territorio ibérico formando parte del ejército de ocupación, integrándose en el frente astur, que correspondía a la provincia de Lusitania.

Tras su efímera pertenencia temporal a la provincia Transduriana ${ }^{44}$, entre los años 13 y 6 estaría asignada a la Hispania Tarraconense, de manera que, en compañía de la legión VI Victrix, o bien tendrían un asentamiento doble común o bien contarían con dos campamentos separados, muy próximos entre sí, en Asturica o en sus proximidades ${ }^{45}$.

En cualquier caso es posible que un destacamento de este cuerpo de tropas permaneciese acuartelado en el suelo de la futura capital del conventus Asturum

\footnotetext{
40 J.RODRÍGUEZ, Historia de las legiones romanas, p.220.

41 E.PERALTA, «Los castros cántabros y los campamentos romanos de Toranzo y de Iguña», Las guerras cántabras, Santander 1999, p.203.

42 M.L.GONZÁLEZ FERNÁNDEZ, "Consideraciones sobre el origen militar de Asturica Augusta», Los finisterres atlánticos en la Antigüedad, Madrid 1996, pp.85 y ss.

43 J.GONZÁLEZ ECHEGARAY, Cantabria antigua, Santander 1986, p.104.

44 Para más detalles remitimos, entre otros, a A.RODRíGUEZ COLMENERO, «El más antiguo documento (año 15 a.C.) hallado en el Noroeste peninsular ibérico», CEG 47 (2000) 9 y ss.

45 E.MARTINO (León y las legiones, pp.55-57, 60 y 95) cree que el acuartelamiento común lo constituiría León, donde la legión X Gemina compartiría campamento con la legión $\mathrm{V}$ Alauda antes de hacerlo con la VI Victrix.
} 
durante bastante tiempo, habiéndose llegado a pensar incluso que hasta los primeros años de nuestra era ${ }^{46}$.

Algún tiempo después, en una fecha todavía sin concretar (para algunos investigadores entre el 15 y el 20), la legión X Gemina trasladría su campamento a Petavonium, en territorio de los astures más meridionales e igualmente en el marco de la provincia Tarraconense ${ }^{47}$.

Ciertos indicios apuntan la posibilidad de que dicho enclave pudo constituir la base campamental de esta unidad legionaria ya desde los años de las guerras astur-cántabras, al menos por tanto desde el año 25 a.C. ${ }^{48}$.

Resulta evidente que el campamento de la legión X Gemina se hallaría en Petavonium (Rosinos de Vidriales, norte de Zamora), pero es posible que en dicho asentamiento los componentes de dicha unidad militar no se hallasen en casi ningún momento acuartelados conjuntamente, sino que diversos destacamentos de la misma se hallarían dispersos en la zona de Sierra Morena y el Noroeste peninsular, aprovechando los recursos de las importantes minas de dichas regiones ${ }^{49}$.

En el transcurso de los primeros años de estancia de este cuerpo legionario en dicho suelo contaría con una serie de contingentes militares auxiliares vinculados a ella, entre los que conocemos el ala II Gallorum Sebosiana, la cohors IIII Gallorum y, posiblemente también, el ala Thracum ${ }^{50}$.

Veteranos de la legión X Gemina, en compañía de los de otras legiones, licenciados en el transcurso de las guerras astur-cántabras, tomarían parte en la fundación de sendas colonias, en primer lugar en Emerita Augusta (provincia Lusitania) en el año 25 y algo después (15-14 a.C.) en Caesaraugusta (provincia Tarraconense) $)^{51}$.

De cualquier forma este cuerpo legionario estaría ya perfectamente acuartelado en Petavonium al menos desde los primeros años de nuestra era (si no antes), contribuyendo, al igual que sucedería con las legiones IIII Macedonica y VI Victrix,

46 A.MORILLO, «Conquista y estrategia: el ejército romano durante el período augusteo y julioclaudio en la región septentrional de la Península lbérica», Arqueología militar romana en Hispania, Madrid 2003, pp.80-81 y 84.

47 A.E. 1976, n. ${ }^{\circ} 289$. Cf. M.V.ROMERO y S.CARRETERO, «Los campamentos y la ciudad de Petavonium», Los orígenes de la ciudad en el Noroeste hispánico, Lugo 1999, p.1078.

48 A.JIMÉNEZ, «El ataque astur del invierno del 25 a.C.», Astorica 16 (1997) 79 y 83-85.

49 N.SANTOS, «Ejército romano y minería del oro en el Norte de la Península lbérica», HAnt 21 (1997) 93 y ss.

50 S.CARRETERO, «El ejército romano del N.O. peninsular durante el Alto Imperio», Gladius 19 (1999) 149.

51 M. ${ }^{a}$ P.GARCÍA-GELABERT («La colonización romana en Hispania y Africa en época de César y Augusto", L'Africa romana III, Sassari 1994, 1198) considera que también Barcino constituyó un lugar de asentamiento de algunos veteranos de esta legión. En este sentido no podemos olvidar que la fundación de dicho emplazamiento romano parece haber tenido lugar por esas mismas fechas: cf. O.GRANADOS e I.RODÁ, «La Barcelona de l’època romana», III Congrès d'història de Barcelona, Barcelona 1994, pp.11-12. 
a la reorganización administrativa emprendida por el Estado romano en las regiones septentrionales hispanas.

Cada una de estas unidades legionarias (con sus respectivos destacamentos y las unidades de tropas auxiliares que dependían de ellas) extenderían su radio de acción por los territorios próximos a sus campamentos, contribuyendo así a la mejora de las infraestructuras viarias, que en última instancia iban a posibilitar la llegada de todo un conjunto de productos de primera necesidad para el normal funcionamiento de los campamentos y recintos militares de menor entidad (castella), con frecuencia emplazados en zonas de enorme importancia estratégica ${ }^{52}$.

No es de extrañar, por tanto, que, con el objetivo de contribuir a estas labores de construcción de calzadas, puentes..., se produjesen frecuentes dislocaciones de destacamentos de estas unidades militares hacia lugares muy alejados de su base campamental.

Además, dos de las fundaciones coloniales llevadas a cabo con veteranos de las legiones que habían participado en los combates del Norte peninsular (Emerita y Caesaraugusta) se convertirían en nudos viarios especialmente significativos, lo que nos lleva a pensar en la existencia de un plan director de la administración romana, tal vez puesto en marcha por Agripa ${ }^{53}$.

En cuanto a los oficiales de este cuerpo de tropas legionarias conocemos un número significativo de centuriones, entre los que destacan: Tito Classio Flavino ${ }^{54}$, originario de Tarraco; Marco Audasio Máximo ${ }^{55}$, procedente de Caldas de Reis; y Saufeis Silón, hallada en Segusio, en los Alpes Cottios ${ }^{56}$.

En lo que respecta al período de servicio de dicha unidad militar en suelo hispano conocemos, al menos, la existencia de 5 tribunos $^{57}$.

\section{CONCLUSIONES}

El final de las guerras astur-cántabras traería consigo una desmilitarización paulatina del Norte peninsular como consecuencia de que la presencia de contingentes tan numerosos de soldados ya no eran precisos para el control estratégicomilitar de las comunidades septentrionales hispanas (cántabros, astures y galaicos).

52 Ver, por ejemplo, F.J.SÁNCHEZ-PALENCIA, «El campamento romano de Valdemeda, Manzaneda (León): ocupación militar y explotación aurífera en el N.O. peninsular», Numantia 2 (1986) 227 y ss.

53 J.M.RODDAZ, «Agripa y la Península Ibérica», Anas 6 (1993) 124.

54 CIL II.4151.

${ }^{55} \mathrm{HAE}$ n. ${ }^{\circ} 1757$ = Roldán n. ${ }^{\circ}$ 570. Cf. N.SANTOS, El ejército y la romanización de Galicia, Oviedo 1988, p.205.

56 CIL V.7255

57 Ver J.M.ROLDÁN, Hispania y el ejército romano. Contribución a la historia social de la España antigua, Salamanca 1974, pp.322 y ss., cuyos testimonios epigráficos recogen los cursus honorum de dichos personajes, así como los años de servicio. 
Sin embargo, se hacía necesaria todavía la contribución de algunas de dichas unidades legionarias (y de las tropas auxiliares vinculadas a ellas) no solo por el control a ejercer sobre dichas comunidades sino, de forma especial, por iniciar las tareas vinculadas al aprovechamiento de los recursos (agropecuarios y mineros) del territorio que habitaban.

Es por ello que un número significativo de las legiones que habían tomado parte en las guerras de conquista ${ }^{58}$ abandonarían el territorio septentrional hispano inmediatamente después de que Agripa diera por finalizados los combates.

Pero eso no significaba que el proceso de militarización del Norte peninsular se diese por cerrado en esos años sino que 3 de dichos cuerpos legionarios (IIII Macedónica, VI Victrix y X Gemina) quedarían estacionados en dicho suelo (estos efectivos militares no integrarían un "ejército de frontera" sino uno de ocupación del territorio, aunque todavía con unos objetivos militares evidentes).

De esta manera asistiremos en tiempos de Augusto, aunque el proceso no se cerrará hasta la época de los julio-claudios, al reclutamiento de unidades de tropas auxiliares a base de elementos astures, lo que permitiría una posibilidad de ascenso social para dichos individuos en el marco de sus unidades organizativas correspondientes.

Las legiones que formaban parte del ejército de ocupación del Norte peninsular actuarían como referente en la formación y adiestramiento militar de estas unidades de tropas auxiliares integradas por astures, galaicos y cántabros, de manera que, a medida que este hecho iba perdiendo fuerza entre las poblaciones septentrionales, irían abandonando el suelo hispano en un proceso que podemos identificar como la segunda fase de desmilitarización del Norte peninsular (primero la legión IIII Macedónica, a continuación la X Gemina y finalmente la VI Victrix).

Ello no implicaría que el territorio de los astures fuese abandonado totalmente por parte del ejército romano, puesto que sabemos que desde el año 74 la legión VII Gemina tendrá su campamento en León, contribuyendo algunas de sus vexillationes (y de las tropas auxiliares con que contaba) a la explotación de los recursos auríferos del Noroeste peninsular como una de las actividades prioritarias de su historia.

58 Ver más detalles en J.M.ROLDÁN, Hispania y el ejército romano, pp. 188 y ss. y N.SANTOS, «EI ejército romano de conquista en el Norte peninsular» (en prensa). 